\title{
Effects of Subacute Exposure of Dibutyl Phthalate on the Homeostatic Model Assessment, Thyroid Function, and Redox Status in Rats
}

\author{
Khalid Abdul Majeed $\mathbb{D},{ }^{1}$ Muhammad Shahbaz Yousaf $\mathbb{D},{ }^{1}$ Muhammad Sajid Tahir, ${ }^{2}$ \\ Aamir Riaz Khan, ${ }^{3}$ Suliman Khan, ${ }^{4}$ Abdullah Arif Saeed, ${ }^{1}$ and Habib Rehman ${ }^{1}$ \\ ${ }^{1}$ Department of Physiology, University of Veterinary and Animal Sciences, Lahore 54600, Pakistan \\ ${ }^{2}$ School of Chemistry and Molecular Biosciences, University of Queensland, Brisbane, Queensland, Australia 4072 \\ ${ }^{3}$ Veterinary Research Institute, Lahore, Pakistan 54000 \\ ${ }^{4}$ Department of Veterinary Physiology, Lasbela University of Agriculture, Water and Marine Sciences, Uthal, \\ Balochistan 90150, Pakistan \\ Correspondence should be addressed to Muhammad Shahbaz Yousaf; drmshahbaz@uvas.edu.pk
}

Received 17 February 2021; Accepted 24 July 2021; Published 4 August 2021

Academic Editor: Mateusz Maciejczyk

Copyright (C) 2021 Khalid Abdul Majeed et al. This is an open access article distributed under the Creative Commons Attribution License, which permits unrestricted use, distribution, and reproduction in any medium, provided the original work is properly cited.

\begin{abstract}
Dibutyl phthalate is an endocrine disruptor used in a wide range of industrial and agriculture applications. The present study focuses on elucidating the effect of subacute exposure (4-weeks) of DBP on insulin and its sensitivity indexes, oxidative status, thyroid function, energy metabolites, serum biochemistry, and anthropometry in rats. A total of 64 rats were divided into 4 treatment groups as $\mathrm{mg} \mathrm{DBP} / \mathrm{Kg}$ body weight per day: (a) $0 \mathrm{mg} / \mathrm{Kg}$ (control), (b) $10 \mathrm{mg} / \mathrm{Kg}$ (DBP-10), (c) $50 \mathrm{mg} / \mathrm{Kg}$ (DBP-50), and (d) $100 \mathrm{mg} / \mathrm{Kg}$ (DBP-100). The rats in each treatment $(n=16)$ were further divided into male $(n=8)$ and female $(n=8)$ rats for studying treatment and gender interactions. Intraperitoneal glucose tolerance test (IPGTT) was performed on the $21^{\text {st }}$ day. Anthropometry, nutritional determinants, fasting plasma glucose, fasting plasma insulin, homeostatic model assessment (HOMA), thyroid hormones, energy metabolites, and oxidative status were studied during the experimental period. Two-way ANOVA was used to analyze the data $(p<0.05)$. Tukey's posthoc test was used for pair-wise comparisons. DBP increased body weight gain and feed efficiency in an inverted nonmonotonic $U$-shaped fashion. Hyperglycemia and increased blood glucose area under the curve were observed in DBP-100 at 120 minutes in IPGTT. The HOMA also showed a linear monotonic contrast. Thyroxin decreased significantly in the DBP-100 rats, whereas malondialdehyde, nonesterified fatty acids, and beta hydroxyl butyrate were increased with the DBP treatments. In conclusion, DBP could be attributed to the development of hyperglycemia and insulin resistance in rats. Further investigations into the lipid peroxidation pathways can improve our understanding of the mechanisms involved in metabolic disruption.
\end{abstract}

\section{Introduction}

Dibutyl phthalate (DBP) is a potent endocrine disruptor (ED) that can interfere with the homeostatic mechanisms of natural hormones. It is widely used in various everyday commercial products like cosmetics, varnishes, adhesives, plastic food wraps, inks, lacquers, and pharmaceuticals. Because of this extensive use, "One Health" is constantly exposed to the ill effects of DBP. The exposure is predomi- nately through ingestion, inhalation, and absorption through the skin. DBP has contaminated food products like eggs [1], milk [2], meat [3], and drinking water ([4] [5]).

DBP belongs to phthalates that have the potential to interact with nuclear receptors PPARs (peroxisome proliferator-activated receptors) [6], the natural ligands of which are fatty acids and eicosanoids [7]. There is evidence that PPARs may be involved in chronic diseases like diabetes and obesity as reviewed [8]. Several epidemiological studies 
have also associated phthalates with diabetes. Urinary levels of phthalate metabolites are associated with prevalent diabetes in women [9], risk of type 2 diabetes in nurses [10], and increased waist circumference and insulin resistance in adult males [11] in the United States. Similarly, circulating levels of phthalates and their metabolites have been associated with diabetes prevalence in elderly individuals in Sweden [12] and glucose metabolism in peripubescent children in Mexico [13].

In experimental studies, DBP administered through oral route [14], inhalation [15], and intraperitoneal injection [16] has shown to increase the cytochrome P450 system that is associated with lipid and glucose homeostasis in rats. DBP has also been shown to disrupt evolutionarily conserved insulin and glucagon-like signaling pathways in Drosophila males [17]. Phthalates, other than DBP, have been shown to adversely affect the expression of insulin receptors and glucose transporter 4 (GLUT4) gene expression in myotubes [18]. There is a dire need to explore whether DBP can alter glucose metabolism and potentiate the risk of diabetes and insulin resistance. Insulin is a vital hormone involved in glucose uptake and inhibition of lipolysis in the adipose tissue through insulin receptors (IR) and its substrates (IRSs) [19]. The present study is designed to elucidate the effects of subacute exposure of DBP at above and below the no observed adverse effect level (NOAEL, DBP $50 \mathrm{mg} / \mathrm{kg}$ ) on insulin, homeostatic model assessment (HOMA), thyroid function, and redox status in rats.

\section{Materials and Methods}

2.1. Experimental Animals. Sixty-four albino (32/gender) rats were used in the present study. The rats of similar anthropometry were housed in individual cages (Natsume Seisakusho Co. Ltd., Japan) at an experimental animal shed, Department of Physiology, University of Veterinary and Animal Sciences (UVAS), with free access to feed and water. The rats were maintained under 12-h light and 12-h dark cycle with an ambient temperature of $22 \pm 3^{\circ} \mathrm{C}$ and relative humidity of $60-70 \%$. Ethical commission for use of laboratory animals, UVAS, approved the experimental protocol (Directive No. DR/539).

2.2. Experimental Groups. The rats were offered standard rat chow (dietary component percentage by weight; dietary casein 20.5; glucose 20; cornstarch 39.7; cellulose 6; sunflower oil 5.8; vitamins 1; minerals 7). The rats were divided into four groups and administered DBP (Scharalu, Spain) in feed per $\mathrm{kg}$ body weight as (a) $0 \mathrm{mg} / \mathrm{kg}$ DBP per day (control), (b) $10 \mathrm{mg} / \mathrm{kg}$ DBP per day (DBP-10), (c) $50 \mathrm{mg} / \mathrm{kg}$ DBP per day (DBP-50), and (d) $100 \mathrm{mg} / \mathrm{kg}$ DBP per day (DBP-100) for a period of 4 weeks. Each group was further subdivided on the basis of gender (male/female). For administration via feed, DBP was solubilized in sunflower oil and mixed in feed.

2.3. Anthropometry and Nutritional Parameters. Body weight (g), body mass gain (g), feed consumption (g/day), energy intake (KJ/day), and feed efficiency (\%) were measured for assessing nutritional parameters. Abdominal circumference (AC), thoracic circumference (TC), AC/TC ratio, body length, and body mass index (BMI) were measured to assess anthropometry. All these parameters were done as described previously $[20,21]$. Relative organ weights (\%) were calculated as described by [22].

2.4. Glucose Tolerance, Fasting Glucose, Fasting Insulin, and Insulin Sensitivity Indexes. Intraperitoneal glucose tolerance test was performed on the $21^{\text {st }}$ day after fasting rats overnight ( $5 \mathrm{pm}$ to $8 \mathrm{am})$. After collecting a fasting blood glucose sample ( 0 minutes), a $10 \%$ glucose solution ( $1 \mathrm{~g} / \mathrm{Kg}$ body weight) was injected intraperitoneally. This was followed by glucose measurements at 30, 60, and 120 minutes after injection. The glucose measurements were taken from tail blood using a blood glucose analyzer (Nipro Diagnostics, TRUEresult ${ }^{\circledR}$ Test strips, Lauderdale, US, Lot PT2857ITR, and PT2755ITR). The area under the blood glucose timeconcentration curve was calculated as described previously [23]. At the end of the $4^{\text {th }}$ week, Fasting plasma glucose (Innoline, Merck, France) and insulin (Glory Bioscience, Del Rio, US, Lot 201506) were measured from serum collected at the end of the study ( $4^{\text {th }}$ week) on Epoch ${ }^{\mathrm{TM}}$ microplate reader (Biotek Instruments Inc. Winooski, US). Insulin sensitivity indexes were calculated as described previously [24].

2.5. Oxidative Stress, Thyroid Function, and Energy Metabolites. Oxidative damage was assessed by measuring serum catalase (BioVision, Inc. Milpitas, US, Lot 9E060773) and malondialdehyde (MDA) (BioVision, Inc. Milpitas, US, Lot 9E200739). Total triiodothyronine (T3) and thyroxin (T4) were estimated using BioCheck (Foster City, US, Lot RN-56911, and RN-56760) kits. For studying energy markers, nonesterified fatty acids (NEFA) (Randox, Crumlin, $\mathrm{UK}$, Lot 350318) and beta-hydroxybutyrate $(\beta-\mathrm{HB})$ (Pointe Scientific, Inc. Canton, US, Lot 633704-018) were estimated in serum.

2.6. Serum Chemistry. Serum chemistry included cholesterol, high-density lipoproteins (HDL), triglycerides, total proteins, albumin (A), globulin (G), and A/G ratio. Enzymes profile included lactate dehydrogenase (LDH), alkaline phosphatase (ALP), aspartate transaminase (AST), alanine transaminase (ALT), gamma-glutamyl transferase (GGT), and creatine kinase (CK). Renal function tests included blood urea nitrogen (BUN), serum creatinine, and uric acid. Commercial kits from Human Diagnostics (Wiesbaden, Germany) were used for all these parameters, except GGT (Chronolab, Barcelona, Spain) and CK (Innoline, Merck, France), and estimated on Epoch $^{\mathrm{TM}}$ microplate spectrophotometer (Biotek Instruments Inc. Winooski, US).

2.7. Statistical Analysis. Data was checked for normality using the Kolmogorov Smirnov test. Data were analyzed by two-way ANOVA using SPSS software (SPSS Inc., Chicago, US, Version 16.0). The factors considered were treatment and gender. Homogeneity of variances was checked using Levene's test. $p$ value less than 0.05 was considered statistically significant, and a $p$ value less than 0.1 was considered a trend. Tukey's posthoc test was used for comparison 
TABLE 1: Effects of subacute exposure of dibutyl phthalate on nutritional determinants and anthropometric parameters of obesity in rats.

\begin{tabular}{|c|c|c|c|c|c|c|c|c|}
\hline & Control & $\begin{array}{c}\mathrm{DBP} \\
10 \mathrm{mg} / \mathrm{kg}\end{array}$ & $\begin{array}{c}\mathrm{DBP} \\
50 \mathrm{mg} / \mathrm{kg}\end{array}$ & $\begin{array}{c}\text { DBP } \\
100 \mathrm{mg} / \mathrm{kg}\end{array}$ & $\begin{array}{c}p \\
\text { (treatment) }\end{array}$ & $\begin{array}{c}p \\
\text { (linear) }\end{array}$ & $\begin{array}{c}p \\
\text { (quadratic) }\end{array}$ & $\begin{array}{c}p \\
\text { (treatment } \times \text { gender) }\end{array}$ \\
\hline Body weight (g) & $187.7 \pm 9.5$ & $205.5 \pm 14.9$ & $204.7 \pm 15.6$ & $192.0 \pm 13.3$ & 0.32 & 0.84 & 0.27 & 0.20 \\
\hline Body weight gain (g) & $61.5 \pm 7.0^{\mathrm{a}}$ & $95.5 \pm 9.8^{\mathrm{b}}$ & $76.0 \pm 11.0^{\mathrm{ab}}$ & $64.0 \pm 12.2^{\mathrm{a}}$ & 0.02 & 0.79 & 0.03 & 0.45 \\
\hline Feed consumed (g/day) & $18.2 \pm 0.57$ & $18.7 \pm 0.56$ & $18.8 \pm 0.56$ & $18.5 \pm 0.7$ & 0.90 & 0.75 & 0.60 & 0.80 \\
\hline Energy intake (KJ/day) & $266.57 \pm 8.4$ & $272.12 \pm 8.3$ & $273.8 \pm 8.3$ & $270.5 \pm 10.3$ & 0.90 & 0.74 & 0.60 & 0.84 \\
\hline Feed efficiency (\%) & $6.4 \pm 0.58^{\mathrm{a}}$ & $8.5 \pm 0.33^{\mathrm{b}}$ & $8.1 \pm 0.45^{\mathrm{bc}}$ & $6.8 \pm 0.50^{\mathrm{ac}}$ & $<0.01$ & 0.90 & $<0.01$ & 0.60 \\
\hline $\begin{array}{l}\text { Thoracic circumference } \\
(\mathrm{cm})\end{array}$ & $11.7 \pm 0.23$ & $12.5 \pm 0.34$ & $12.4 \pm 0.32$ & $12.0 \pm 0.24$ & 0.19 & 0.54 & 0.06 & 0.56 \\
\hline $\begin{array}{l}\text { Abdominal } \\
\text { circumference }(\mathrm{cm})\end{array}$ & $12.7 \pm 0.21$ & $13.7 \pm 0.43$ & $13.5 \pm 0.33$ & $13.3 \pm 0.18$ & 0.14 & 0.32 & 0.08 & 0.30 \\
\hline $\mathrm{AC} / \mathrm{TC}$ & $1.08 \pm 0.01$ & $1.09 \pm 0.01$ & $1.09 \pm 0.01$ & $1.1 \pm 0.02$ & 0.46 & 0.12 & 0.87 & 0.21 \\
\hline Body length $(\mathrm{cm})$ & $18.8 \pm 0.54$ & $19.6 \pm 0.59$ & $19.6 \pm 0.60$ & $18.5 \pm 0.16$ & 0.11 & 0.69 & 0.08 & 0.21 \\
\hline $\mathrm{BMI}\left(\mathrm{g} / \mathrm{cm}^{2}\right)$ & $0.53 \pm 0.02$ & $0.53 \pm 0.02$ & $0.53 \pm 0.02$ & $0.55 \pm 0.04$ & 0.58 & 0.39 & 0.52 & 0.69 \\
\hline
\end{tabular}

Data are presented as mean \pm standard error. Superscripts ${ }^{\text {a-c }}$ within the row indicate significant differences $(p<0.05)$. Two-way ANOVA was used for assessing the effects of treatment and gender. Polynomial contrasts (linear and quadratic) were used to assess monotonic and nonmonotonic responses.

TABLE 2: Effects of subacute exposure of dibutyl phthalate on relative organ weights (\%) in rats.

\begin{tabular}{lcccccccc}
\hline & Control & $\begin{array}{c}\text { DBP } \\
10 \mathrm{mg} / \mathrm{kg}\end{array}$ & $\begin{array}{c}\text { DBP } \\
50 \mathrm{mg} / \mathrm{kg}\end{array}$ & DBP $100 \mathrm{mg} / \mathrm{kg}$ & $p$ (treatment) & $p$ (linear) & $p$ (quadratic) & $p$ (treatment $\times$ gender) \\
\hline Liver & $3.01 \pm 0.16^{\mathrm{a}}$ & $3.48 \pm 0.12^{\mathrm{b}}$ & $3.35 \pm 0.08^{\mathrm{ab}}$ & $3.43 \pm 0.1^{\mathrm{ab}}$ & 0.03 & 0.04 & 0.11 & 0.41 \\
Kidney & $0.73 \pm 0.02^{\mathrm{a}}$ & $0.78 \pm 0.02^{\mathrm{ab}}$ & $0.80 \pm 0.02^{\mathrm{ab}}$ & $0.86 \pm 0.04^{\mathrm{b}}$ & 0.01 & $<0.01$ & 0.81 & 0.20 \\
Heart & $0.33 \pm 0.01$ & $0.34 \pm 0.01$ & $0.29 \pm 0.01$ & $0.31 \pm 0.01$ & 0.10 & 0.17 & 0.63 & 0.51 \\
Lungs & $0.60 \pm 0.04$ & $0.64 \pm 0.04$ & $0.61 \pm 0.03$ & $0.63 \pm 0.04$ & 0.88 & 0.74 & 0.78 & 0.59 \\
Spleen & $0.21 \pm 0.01$ & $0.22 \pm 0.01$ & $0.24 \pm 0.01$ & $0.23 \pm 0.01$ & 0.19 & 0.15 & 0.47 & 0.45 \\
\hline
\end{tabular}

Data are presented as mean \pm standard error. Superscripts ${ }^{\mathrm{a}-\mathrm{b}}$ within the row indicate significant differences $(p<0.05)$. Two-way ANOVA was used for assessing the effects of treatment and gender. Polynomial contrasts (linear and quadratic) were used to assess monotonic and nonmonotonic responses.
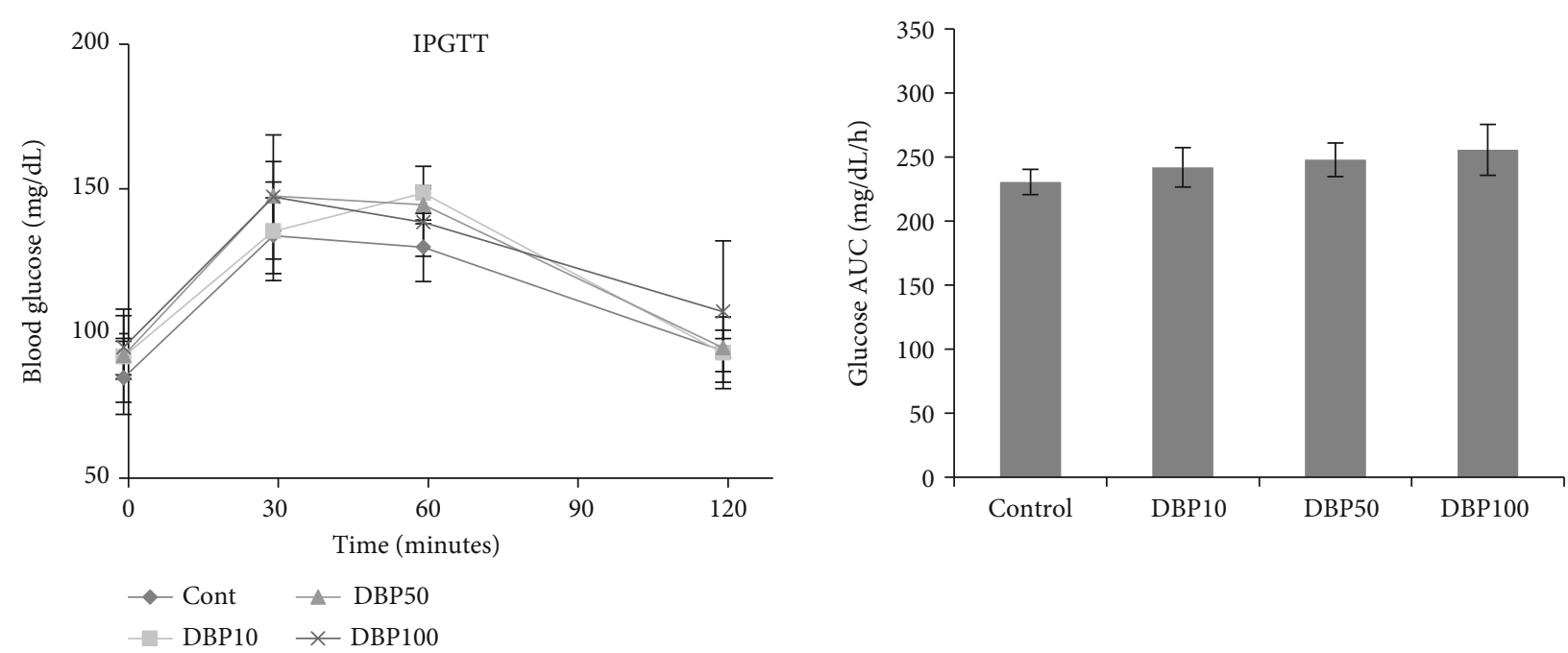

FIGURE 1: Blood glucose in intraperitoneal glucose tolerance test (IPGTT) and blood glucose area under the curve (AUC) in IPGTT. Two-way ANOVA was used for assessing the effects of treatment and gender. 
TABLE 3: Effects of subacute exposure of dibutyl phthalate on fasting glucose, insulin, and insulin sensitivity indexes in rats.

\begin{tabular}{|c|c|c|c|c|c|c|c|c|}
\hline & Control & $\begin{array}{c}\mathrm{DBP} \\
10 \mathrm{mg} / \mathrm{kg}\end{array}$ & $\begin{array}{c}\mathrm{DBP} \\
50 \mathrm{mg} / \mathrm{kg}\end{array}$ & $\begin{array}{c}\text { DBP } \\
100 \mathrm{mg} / \mathrm{kg}\end{array}$ & $\begin{array}{c}p \\
\text { (treatment) }\end{array}$ & $\begin{array}{c}p \\
\text { (linear) }\end{array}$ & $\begin{array}{c}p \\
\text { (quadratic) }\end{array}$ & $\begin{array}{c}p \\
\text { (treatment } \times \text { gender) }\end{array}$ \\
\hline $\begin{array}{l}\text { Fasting glucose } \\
(\mathrm{mg} / \mathrm{dL})\end{array}$ & $89.2 \pm 2.5$ & $93.6 \pm 2.1$ & $98.8 \pm 3.1$ & $97.2 \pm 3.0$ & 0.09 & 0.02 & 0.28 & 0.25 \\
\hline $\begin{array}{l}\text { Fasting insulin } \\
(\mu \mathrm{U} / \mathrm{mL})\end{array}$ & $10.1 \pm 1.0$ & $8.7 \pm 0.6$ & $10.2 \pm 0.8$ & $10.7 \pm 1.1$ & 0.28 & 0.38 & 0.25 & 0.20 \\
\hline HOMA-IR & $0.35 \pm 0.03$ & $0.35 \pm 0.02$ & $0.43 \pm 0.04$ & $0.45 \pm 0.06$ & 0.13 & 0.05 & 0.87 & 0.21 \\
\hline QUICKI & $0.34 \pm 0.01$ & $0.34 \pm 0.01$ & $0.33 \pm 0.01$ & $0.33 \pm 0.01$ & 0.30 & 0.12 & 0.91 & 0.22 \\
\hline FGIR $\left(\mathrm{mg} / 10^{-4} \mathrm{U}\right)$ & $10.0 \pm 0.83$ & $10.2 \pm 0.68$ & $10.0 \pm 0.73$ & $8.6 \pm 1.2$ & 0.52 & 0.26 & 0.41 & 0.20 \\
\hline
\end{tabular}

Data are presented as mean \pm standard error. Two-way ANOVA was used for assessing the effects of treatment and gender. Polynomial contrasts (linear and quadratic) were used to assess monotonic and nonmonotonic responses.

TABLE 4: Effect of subacute exposure of dibutyl phthalate on thyroid hormones, oxidative stress, and energy metabolites in rats.

\begin{tabular}{|c|c|c|c|c|c|c|c|c|}
\hline & Control & $\begin{array}{c}\mathrm{DBP} \\
10 \mathrm{mg} / \mathrm{kg}\end{array}$ & $\begin{array}{c}\mathrm{DBP} \\
50 \mathrm{mg} / \mathrm{kg}\end{array}$ & $\begin{array}{c}\text { DBP } \\
100 \mathrm{mg} / \mathrm{kg}\end{array}$ & $\begin{array}{c}p \\
\text { (treatment) }\end{array}$ & $\begin{array}{c}p \\
\text { (linear) }\end{array}$ & $\begin{array}{c}p \\
\text { (quadratic) }\end{array}$ & $\begin{array}{c}p \\
\text { (treatment } \times \text { gender })\end{array}$ \\
\hline Total T3 (ng/dL) & $97.15 \pm 0.2$ & $97.12 \pm 0.6$ & $95.14 \pm 0.9$ & $96.83 \pm 0.8$ & 0.10 & 0.71 & 0.19 & 0.38 \\
\hline Total T4 $(\mu \mathrm{g} / \mathrm{dL})$ & $8.27 \pm 0.4^{\mathrm{a}}$ & $7.11 \pm 0.3^{\mathrm{ab}}$ & $6.94 \pm 0.5^{\mathrm{ab}}$ & $5.79 \pm 0.8^{\mathrm{b}}$ & 0.01 & $<0.01$ & 0.90 & 0.21 \\
\hline $\begin{array}{l}\text { Catalase activity } \\
(\mathrm{nmol} / \mathrm{min} / \mathrm{mL})\end{array}$ & $166.5 \pm 19.6$ & $140.8 \pm 17.6$ & $144.9 \pm 13.0$ & $122.5 \pm 12.5$ & 0.79 & 0.39 & 0.91 & 0.23 \\
\hline $\begin{array}{l}\text { Malondialdehyde } \\
\text { (nmol/mL) }\end{array}$ & $1.38 \pm 0.03^{\mathrm{a}}$ & $1.87 \pm 0.1^{\mathrm{ab}}$ & $1.97 \pm 0.2^{\mathrm{ab}}$ & $2.23 \pm 0.2^{\mathrm{b}}$ & 0.01 & 0.01 & 0.56 & 0.66 \\
\hline NEFA (mmol/L) & $0.81 \pm 0.04^{\mathrm{a}}$ & $1.28 \pm 0.1^{\mathrm{b}}$ & $1.09 \pm 0.04^{\mathrm{ab}}$ & $1.07 \pm 0.08^{\mathrm{ab}}$ & 0.04 & 0.13 & 0.02 & 0.20 \\
\hline$\beta-\mathrm{HB}(\mathrm{mmol} / \mathrm{L})$ & $0.87 \pm 0.03^{\mathrm{a}}$ & $1.09 \pm 0.03^{\mathrm{b}}$ & $1.05 \pm 0.03^{\mathrm{b}}$ & $1.04 \pm 0.04^{\mathrm{b}}$ & $<0.01$ & 0.03 & 0.10 & 0.24 \\
\hline
\end{tabular}

Data are presented as mean \pm standard error. Superscripts ${ }^{\mathrm{a}-\mathrm{b}}$ within the row indicate significant differences $(p<0.05)$. Two-way ANOVA was used for assessing the effects of treatment and gender. Polynomial contrasts (linear and quadratic) were used to assess monotonic and nonmonotonic responses.

between the treated groups. Polynomial contrasts were used to assess monotonic and nonmonotonic responses.

\section{Results}

The effects of subacute exposure of dibutyl phthalate on nutritional determinants and anthropometry are shown in Table 1 . Body weight gain was affected in a $U$-shaped nonmonotonic response with an increase in DBP-10 compared with the control group $(p=0.02)$. Similarly, feed efficiency was also affected by an increase in DBP-10 compared with the control animals $(p=<0.01)$. $U$-shaped nonmonotonic trends were observed for thoracic circumference $(p=0.06)$, abdominal circumference $(p=0.08)$, and body length $(p=0.08)$ with an increase in DBP-10 compared with the control rats. Relative weights of the liver and kidney increased with significance in the DBP-10 and DBP-100, respectively, compared with the control group (Table 2 ).

A significant effect of DBP treatment $(p=0.017)$ and treatment into gender interaction $(p=<0.01)$ was observed on blood glucose at 120 minutes in IPGTT. Similarly, a trend was observed for DBP treatment $(p=0.076)$ and treatment into gender interaction $(p=0.026)$ for blood glucose AUC (Figure 1). Considering DBP into gender interaction for blood glucose at 120 minutes in IPGTT, DBP-100 male was statistically different from males of the control, DBP-10, and DBP-50 $(p=<0.01)$. Similarly, the control males were also statistically different from DBP-100 for blood glucose AUC $(p=0.05)$. No effects between the control and DBPtreated female rats were observed for IPGTT and AUC. An overall trend was observed for fasting glucose $(p=0.09)$. A linear monotonic response was observed for fasting glucose with a $p$ value of 0.02 . Similarly, the homeostatic model assessment of insulin resistance (HOMA-IR) was linearly significant with a $p$ value of 0.05 . No other effects of subacute exposure of dibutyl phthalate were observed on fasting insulin, quantitative insulin sensitivity check index (QUICIKI), and fasting glucose-insulin ratio (FGIR) (Table 3). No effects of the DBP treatment were observed on the IR $(p=0.9)$ and IRS-1 ( $p=0.7)$ mRNA expression (Data not shown).

A trend $(p=0.1)$ of the decrease in total T3 was observed by the DBP treatments. However, a significant decrease was observed for total T4 compared with the control rats $(p=0.01)$. The serum catalase was not affected by any treatment. The serum MDA was increased significantly in the DBP-100 compared with the control rats $(p=0.01)$. The serum NEFA concentrations were increased in the DBP-10 rats compared with the control rats $(p=0.04)$. The serum $\beta$-HB was increased in all the DBP treated groups compared with the control group $(p<0.01)$ (Table 4$)$. No effect of DBP treatment was observed on the lipid profile and serum proteins. However, a decreasing trend for linear contrast was observed for total proteins $(p=0.09)$ and globulins $(p=0.08)$. No effect was observed on BUN, serum creatinine, 
TABLE 5: Effects of subacute exposure of dibutyl phthalate on the serum biochemistry in rats.

\begin{tabular}{|c|c|c|c|c|c|c|c|c|}
\hline & Control & $\begin{array}{c}\mathrm{DBP} \\
10 \mathrm{mg} / \mathrm{kg}\end{array}$ & $\begin{array}{c}\mathrm{DBP} \\
50 \mathrm{mg} / \mathrm{kg}\end{array}$ & $\begin{array}{c}\text { DBP } \\
100 \mathrm{mg} / \mathrm{kg}\end{array}$ & $\begin{array}{c}p \\
\text { (treatment) }\end{array}$ & $\begin{array}{c}p \\
\text { (linear) }\end{array}$ & $\begin{array}{c}p \\
\text { (quadratic) }\end{array}$ & $\begin{array}{c}p \\
\text { (treatment } \times \text { gender }\end{array}$ \\
\hline $\begin{array}{l}\text { Cholesterol } \\
(\mathrm{mg} / \mathrm{dL})\end{array}$ & $86.91 \pm 5.3$ & $76.35 \pm 4.2$ & $81.47 \pm 4.5$ & $84.70 \pm 4.8$ & 0.18 & 0.88 & 0.14 & 0.65 \\
\hline $\begin{array}{l}\text { Triglycerides } \\
(\mathrm{mg} / \mathrm{dL})\end{array}$ & $114.54 \pm 4.4$ & $113.08 \pm 4.7$ & $118.79 \pm 1.7$ & $114.51 \pm 4.1$ & 0.60 & 0.75 & 0.71 & 0.20 \\
\hline HDL (mg/dL) & $44.46 \pm 1.2$ & $44.57 \pm 2.2$ & $35.82 \pm 5.1$ & $38.25 \pm 5.5$ & 0.40 & 0.15 & 0.74 & 0.43 \\
\hline $\begin{array}{l}\text { Total protein } \\
(\mathrm{g} / \mathrm{dL})\end{array}$ & $6.92 \pm 0.5$ & $6.19 \pm 0.4$ & $6.18 \pm 0.3$ & $5.95 \pm 0.2$ & 0.28 & 0.09 & 0.51 & 0.17 \\
\hline Albumin (g/dL) & $3.29 \pm 0.2$ & $2.91 \pm 0.1$ & $3.05 \pm 0.1$ & $3.27 \pm 0.1$ & 0.16 & 0.89 & 0.13 & 0.20 \\
\hline Globulin (g/dL) & $3.01 \pm 0.4$ & $2.72 \pm 0.3$ & $2.62 \pm 0.3$ & $2.24 \pm 0.2$ & 0.26 & 0.08 & 0.88 & 0.21 \\
\hline $\mathrm{A} / \mathrm{G}$ ratio & $1.75 \pm 0.7$ & $1.16 \pm 0.1$ & $1.25 \pm 0.1$ & $1.54 \pm 0.1$ & 0.58 & 0.73 & 0.22 & 0.25 \\
\hline BUN (mg/dL) & $24.75 \pm 1.6$ & $24.95 \pm 1.2$ & $25.10 \pm 2.2$ & $21.66 \pm 1.4$ & 0.29 & 0.22 & 0.27 & 0.28 \\
\hline Creatinine $(\mathrm{mg} / \mathrm{dL})$ & $0.78 \pm 0.1$ & $0.85 \pm 0.2$ & $0.98 \pm 0.2$ & $0.85 \pm 0.1$ & 0.77 & 0.61 & 0.50 & 0.33 \\
\hline Uric acid (mg/dL) & $5.86 \pm 0.2$ & $5.63 \pm 0.3$ & $5.69 \pm 0.2$ & $5.03 \pm 0.1$ & 0.13 & 0.12 & 0.46 & 0.17 \\
\hline $\operatorname{ALT}(\mathrm{U} / \mathrm{L})$ & $39.16 \pm 3.8$ & $32.40 \pm 3.0$ & $37.58 \pm 3.7$ & $42.11 \pm 6.4$ & 0.49 & 0.43 & 0.20 & 0.83 \\
\hline AST (U/L) & $86.95 \pm 3.5$ & $78.55 \pm 5.8$ & $86.65 \pm 5.8$ & $95.46 \pm 7.6$ & 0.48 & 0.23 & 0.14 & 0.81 \\
\hline $\operatorname{ALP}(\mathrm{U} / \mathrm{L})$ & $96.42 \pm 12.6$ & $128.16 \pm 14.5$ & $139.26 \pm 18.4$ & $133.04 \pm 16.1$ & 0.53 & 0.22 & 0.35 & 0.71 \\
\hline LDH (U/L) & $442.50 \pm 51.1$ & $510.83 \pm 29.8$ & $464.25 \pm 44.0$ & $513.33 \pm 37.6$ & 0.78 & 0.51 & 0.88 & 0.67 \\
\hline GGT (U/L) & $2.04 \pm 0.4$ & $2.40 \pm 0.4$ & $1.86 \pm 0.2$ & $1.93 \pm 0.2$ & 0.74 & 0.61 & 0.69 & 0.43 \\
\hline CK (U/L) & $420.75 \pm 63.7$ & $464.8 \pm 48.9$ & $302.7 \pm 32.7$ & $283.8 \pm 23.63$ & 0.06 & 0.03 & 0.58 & 0.19 \\
\hline
\end{tabular}

Data are presented as mean \pm standard error. Two-way ANOVA was used for assessing the effects of treatment and gender. Polynomial contrasts (linear and quadratic) were used to assess monotonic and nonmonotonic responses.

uric acid, ALT, AST, ALP, LDH, and GGT. A trend for serum CK was observed only $(p=0.06)$ (Table 5).

\section{Discussion}

Phthalates are extensively used in various commercial products and are therefore ubiquitous in our environment. DBP is an important phthalate, with a wide range of applications in various daily used products. Marsman [25] in detail has covered the effects of DBP in the national toxicology program technical reports. However, the doses used in that particular report were high. The traditional concept of dosedependent hazardous effects has been questioned as several EDs produce toxic effects at low doses that are not observed at higher doses [26]. A similar low dose effect for DBP has been reported by Lee and Veeramachaneni [27], where DBP dose as low as $0.1 \mathrm{mg} / \mathrm{Kg}$ disrupted spermatogenesis in a frog. The present experiment determines the effects of subacute exposure of low concentrations of DBP on insulin and its sensitivity indexes, oxidative status, thyroid function, energy metabolites, serum chemistry, and anthropometry in rats.

No effect of DBP was observed on body weight. However, body weight gain increased significantly in lower doses (DBP-10), and a finding also observed in our subchronic exposure trial [28]. An increase in weight gain could be due to fat deposition because DBP can lead to PPAR pathway activation [29] which can cause adiposity. An inverted non- monotonic response was observed for feed efficiency that relates directly to body weight gain. However, Marsman [25] and Ema et al. [30] have reported decreased body weight gain. This could be due to high exposure DBP doses of $250 \mathrm{mg} / \mathrm{Kg}$ and above. In females in the US, the metabolite of DBP, monobutyl phthalate (MBP), has been associated with faster prospective weight gains in a dose-response fashion [31]. No effects on anthropometry were observed, contrary to our subchronic exposure trail of DBP where the $\mathrm{AC} / \mathrm{TC}$ ratio and the body mass index (BMI) were increased [28]. This could be clearly due to the length of exposure to DBP. A positive association has been reported between MBP, BMI, and circumference of the waist in Chinese and US studies in children [32, 33].

Blood glucose was higher at 120 minutes after IPGTT in DBP-100 males. Similarly, blood glucose AUC was also higher for DBP-100 males only compared with the control. Fasting plasma glucose showed a trend of increase in a linear monotonic fashion. The HOMA-IR also showed a linear monotonic significance. DBP is shown to cause hyperglycemia in Drosophila male flies by disrupting conserved insulin and glucagon-like signaling [17]. The HOMA-IR is an appropriate measure of insulin resistance in the development of type II diabetes [34]. DBP is also reported to have a strong influence on the synergism of action of a mixture of bisphenols A, S, and F, diethyl phthalate (DEP), and bisphenol A diglycidyl ether [35]. Therefore, the presence of DBP in the environment alongside other pollutants can augment the 
linear trend observed for fasting glucose and HOMA-IR (Table 3). In this context, combined effects of DBP and DEP have been shown to induce pancreatic beta-cell apoptosis in rat insulinoma cells [36].

The liver and kidney weights relative to body weight were increased in the DBP-10 and DBP-100 animals, respectively, compared with the control animals. However, no effects on liver enzymes and kidney function tests were observed in the present study of subacute exposure. The subchronic exposure of DBP had a negative impact on the liver and kidney functioning [28]. The present enlargement in the liver and kidney due to subacute exposure of DBP without changes in liver and kidney function tests is unclear. Histopathological examination of the liver and kidney can provide valuable information in this context. A trend for a decrease in total proteins $(p=0.09)$ and globulins $(p=0.08)$ was observed in a linear monotonic polynomial contrast. The decreased total proteins and globulins could be related to increased relative liver weight in the present study. A decreasing trend was observed in serum CK for the DBP-50 and DBP-100 exposed rats in a linear monotonic fashion. DBP could inhibit the acetylcholinesterase enzyme [37] and is known to increase tone in muscles [38]. The continuous exposure for 4 weeks could have led to a reduction in muscle mass that could have lowered serum $\mathrm{CK}$, as is observed in alcoholics [39]. Also, subnormal levels of CK are observed in connective tissue disorders, even in the presence of histologically and clinically active myositis [40].

In this study, DBP decreased total T4 and showed a trend of decrease in total T3. The findings are consistent with a high dose DBP exposure [41] and several epidemiological reports $[42,43]$. The decrease can be attributed to a disruption in thyroid signaling, as DBP and its metabolite have been shown to possess thyroid hormone receptor antagonistic activities in Xenopus laevis [44]. Low doses of DBP are shown to aggravate chronic lymphocytic thyroiditis, a common autoimmune disorder through increased oxidative stress [45]. Oxidative stress through reactive oxygen species is important in autoimmune conditions because their accumulation may be toxic to the DNA. The serum catalase was not affected but serum MDA was significantly increased in the DBP-100 rats compared with the control rats. Testicular catalase has been shown to decrease in rats after exposure to DBP [46]. On the contrary, DBP increased the catalase and MDA levels in Wistar rats [47] and in Karenia brevis algae [48]. Recently, a mixture of DBP along with bisphenol A and DEP has been shown to change the redox status in the rat pancreatic tissue [49]. An insight into the intermediate products of lipid peroxidation and enzymes that generate these products could provide fruitful information for the present study. A similar mechanism of lipid peroxidation due to deleterious effects of reactive oxygen species on spermatozoa has been reported by Baralić et al. [50] where MDA levels were increased after exposure to DBP, DEP, and bisphenol A. Increased NEFA concentrations were observed in DBP-10, whereas $\beta$-HB was increased in all the DBP-treated groups. Sustained reduction in systemic NEFA has been shown to improve insulin sensitivity without restoration of the oxidative capacity of mitochondria [51]. Diabe- tes is an important cause of elevated blood ketones that includes $\beta$ - $\mathrm{HB}$, acetoacetate, and acetone leading to ketoacidosis [52]. Acetoacetate, but not $\beta-\mathrm{HB}$, has been shown to cause an increase in lipid peroxidation [53].

In conclusion, the DBP could be attributed to the development of hyperglycemia and insulin resistance in rats. Further investigations into the lipid peroxidation pathways can improve our understanding of the mechanisms involved in metabolic disruption.

\section{Data Availability}

Data is available through institutional review board, Department of Physiology, UVAS.

\section{Conflicts of Interest}

The authors declare that they have no conflicts of interest.

\section{References}

[1] M. Ishida, K. Suyama, and S. Adachi, "Occurrence of dibutyl and di (2-ethylhexyl) phthalate in chicken eggs," Journal of Agricultural and Food Chemistry, vol. 29, no. 1, pp. 72-74, 1981.

[2] T. Fierens, M. Van Holderbeke, H. Willems, S. De Henauw, and I. Sioen, "Phthalates in Belgian cow's milk and the role of feed and other contamination pathways at farm level," Food and Chemical Toxicology, vol. 50, no. 8, pp. 2945-2953, 2012.

[3] L. Castle, A. J. Mercer, J. R. Startin, and J. Gilbert, "Migration from plasticized films into foods. 2. Migration of di-(2-ethylhexyl) adipate from PVC films used for retail food packaging," Food Additives \& Contaminants, vol. 4, no. 4, pp. 399-406, 1987.

[4] N. Domínguez-Morueco, S. González-Alonso, and Y. Valcárcel, "Phthalate occurrence in rivers and tap water from Central Spain," Science of the Total Environment, vol. 500, pp. 139-146, 2014.

[5] J. Santana, C. Giraudi, E. Marengo et al., "Preliminary toxicological assessment of phthalate esters from drinking water consumed in Portugal," Environmental Science and Pollution Research, vol. 21, no. 2, pp. 1380-1390, 2014.

[6] C. H. Hurst and D. J. Waxman, "Activation of PPAR and PPAR by environmental phthalate monoesters," Toxicological Sciences, vol. 74, no. 2, pp. 297-308, 2003.

[7] J. Berger and D. E. Moller, "The mechanisms of action of PPARs," Annual Review of Medicine, vol. 53, no. 1, pp. 409435, 2002.

[8] S. Kersten, B. Desvergne, and W. Wahli, "Roles of PPARs in health and disease," Nature, vol. 405, no. 6785, pp. 421-424, 2000.

[9] T. James-Todd, R. Stahlhut, J. D. Meeker et al., "Urinary phthalate metabolite concentrations and diabetes among women in the National Health and nutrition examination survey (NHANES) 2001-2008," Environmental Health Perspectives, vol. 120, no. 9, pp. 1307-1313, 2012.

[10] Q. Sun, M. C. Cornelis, M. K. Townsend et al., "Association of urinary concentrations of bisphenol A and phthalate metabolites with risk of type 2 diabetes: a prospective investigation in the Nurses' Health Study (NHS) and NHSII cohorts," Environmental Health Perspectives, vol. 122, no. 6, pp. 616-623, 2014. 
[11] R. W. Stahlhut, E. van Wijngaarden, T. D. Dye, S. Cook, and S. H. Swan, "Concentrations of urinary phthalate metabolites are associated with increased waist circumference and insulin resistance in adult U.S. males," Environmental Health Perspectives, vol. 115, no. 6, pp. 876-882, 2007.

[12] P. M. Lind, B. Zethelius, and L. Lind, "Circulating levels of phthalate metabolites are associated with prevalent diabetes in the elderly," Diabetes Care, vol. 35, no. 7, pp. 1519-1524, 2012.

[13] D. J. Watkins, K. E. Peterson, K. K. Ferguson et al., "Relating phthalate and BPA exposure to metabolism in peripubescence: the role of exposure timing, sex, and puberty," The Journal of Clinical Endocrinology, vol. 101, no. 1, pp. 79-88, 2016.

[14] F. Walseth and O. G. Nilsen, "Phthalate esters: effects of orally administered dibutylphthalate on cytochrome P-450 mediated metabolism in rat liver and lung," Basic and Clinical Pharmacology and Toxicology, vol. 59, no. 4, pp. 263-269, 1986.

[15] F. Walseth and O. G. Nilsen, "Phthalate esters," Archives of Toxicology, vol. 55, no. 2, pp. 132-136, 1984.

[16] F. Walseth, R. Toftgård, and O. G. Nilsen, "Phthalate esters I: effects on cytochrome P-450 mediated metabolism in rat liver and lung, serum enzymatic activities and serum protein levels," Archives of Toxicology, vol. 50, no. 1, pp. 1-10, 1982.

[17] M. J. Williams, L. Wiemerslage, P. Gohel, S. Kheder, L. V. Kothegala, and H. B. Schiöth, "Dibutyl phthalate exposure disrupts evolutionarily conserved insulin and glucagon-like signaling in Drosophila males," Endocrinology, vol. 157, no. 6, pp. 2309-2321, 2016.

[18] P. Rajesh and K. Balasubramanian, "Di (2-ethylhexyl) phthalate exposure impairs insulin receptor and glucose transporter 4 gene expression in L6 myotubes," Human and Experimental Toxicology, vol. 33, no. 7, pp. 685-700, 2014.

[19] F. Renström, J. Burén, and J. W. Eriksson, "Insulin receptor substrates-1 and -2 are both depleted but via different mechanisms after down-regulation of glucose transport in rat adipocytes," Endocrinology, vol. 146, no. 7, pp. 3044-3051, 2005.

[20] E. Novelli, Y. Diniz, C. Galhardi et al., "Anthropometrical parameters and markers of obesity in rats," Laboratory Animals, vol. 41, no. 1, pp. 111-119, 2007.

[21] Y. Sant'Diniz, L. A. Faine, C. M. Galhardi et al., "Monosodium glutamate in standard and high-fiber diets: metabolic syndrome and oxidative stress in rats," Nutrition, vol. 21, no. 6, pp. 749-755, 2005.

[22] M. Żebrowska-Gamdzyk, M. Maciejczyk, A. Zalewska, K. Guzińska-Ustymowicz, A. Tokajuk, and H. Car, "Whey protein concentrate WPC-80 intensifies glycoconjugate catabolism and induces oxidative stress in the liver of rats," Nutrients, vol. 10, no. 9, p. 1178, 2018.

[23] Q. Zhang, X. Sun, X. Xiao et al., "Maternal chromium restriction leads to glucose metabolism imbalance in mice offspring through insulin signaling and Wnt signaling pathways," International Journal of Molecular Sciences, vol. 17, no. 10, p. 1767, 2016.

[24] J. Cacho, J. Sevillano, J. de Castro, E. Herrera, and M. P. Ramos, "Validation of simple indexes to assess insulin sensitivity during pregnancy in Wistar and Sprague-Dawley rats," American Journal of Physiology-Endocrinology and Metabolism, vol. 295, no. 5, 2008.

[25] D. Marsman, "NTP technical report on the toxicity studies of Dibutyl phthalate (CAS no. 84-74-2) administered in feed to F344/N rats and B6C3F1 mice," Toxicity Report Series, vol. 30, 1995.
[26] L. N. Vandenberg, T. Colborn, T. B. Hayes et al., "Hormones and endocrine-disrupting chemicals: low-dose effects and nonmonotonic dose responses," Endocrine Reviews, vol. 33, no. 3, pp. 378-455, 2012.

[27] S. K. Lee and D. R. Veeramachaneni, "Subchronic exposure to low concentrations of di-n-butyl phthalate disrupts spermatogenesis in Xenopus laevis frogs," Toxicological Sciences, vol. 84, no. 2, pp. 394-407, 2005.

[28] K. A. Majeed, H. U. Rehman, M. S. Yousaf et al., "Sub-chronic exposure to low concentration of dibutyl phthalate affects anthropometric parameters and markers of obesity in rats," Environmental Science and Pollution Research, vol. 24, no. 32, pp. 25462-25467, 2017.

[29] T. Kobayashi, S. Niimi, T. Kawanishi, M. Fukuoka, and T. Hayakawa, "Changes in peroxisome proliferator-activated receptor $\gamma$-regulated gene expression and inhibin/activin-follistatin system gene expression in rat testis after an administration of di- _n_ -butyl phthalate," Toxicology Letters, vol. 138, no. 3, pp. 215-225, 2003.

[30] M. Ema, E. Miyawaki, and K. Kawashima, "Effects of dibutyl phthalate on reproductive function in pregnant and pseudopregnant rats," Reproductive Toxicology, vol. 14, no. 1, pp. 13-19, 2000.

[31] Y. Song, R. Hauser, F. Hu, A. Franke, S. Liu, and Q. Sun, "Urinary concentrations of bisphenol A and phthalate metabolites and weight change: a prospective investigation in US women," International Journal of Obesity, vol. 38, no. 12, pp. 1532-1537, 2014.

[32] S. L. Teitelbaum, N. Mervish, E. L. Moshier et al., "Associations between phthalate metabolite urinary concentrations and body size measures in new York City children," Environmental Research, vol. 112, pp. 186-193, 2012.

[33] H. Wang, Y. Zhou, C. Tang et al., "Urinary phthalate metabolites are associated with body mass index and waist circumference in Chinese school children," Plo S One, vol. 8, no. 2, 2013.

[34] D. Matthews, J. Hosker, A. Rudenski, B. Naylor, D. Treacher, and R. Turner, "Homeostasis model assessment: insulin resistance and ?-cell function from fasting plasma glucose and insulin concentrations in man," Diabetologia, vol. 28, no. 7 , pp. 412-419, 1985.

[35] N. Jatkowska, B. Kudłak, P. Lewandowska, W. Liu, M. J. Williams, and H. B. Schiöth, "Identification of synergistic and antagonistic actions of environmental pollutants: Bisphenols $\mathrm{A}, \mathrm{S}$ and $\mathrm{F}$ in the presence of DEP, DBP, BADGE and BADGE $2 \mathrm{HCl}$ in three component mixtures," Science of the Total Environment, vol. 767, p. 144286, 2021.

[36] L. Li, F. Wang, J. Zhang et al., "Typical phthalic acid esters induce apoptosis by regulating the PI3K/Akt/Bcl-2 signaling pathway in rat insulinoma cells," Ecotoxicology and Environmental Safety, vol. 208, p. 111461, 2021.

[37] J. Jee, J. Koo, Y. Keum, K. Park, S. Choi, and J. Kang, "Effects of dibutyl phthalate and di-ethylhexyl phthalate on acetylcholinesterase activity in bagrid catfish, Pseudobagrus fulvidraco (Richardson)," Journal of Applied Ichthyology, vol. 25, no. 6, pp. 771-775, 2009.

[38] I. A. Tavares, A. Bennett, J. D. Gaffen, H. R. Morris, and G. W. Taylor, "The biological activities of phthalate esters on rat gastric muscle," European Journal of Pharmacology, vol. 106, no. 2, pp. 449-452, 1984.

[39] A. Nanji and D. Blank, "Low serum creatine kinase activity in patients with alcoholic liver disease," Clinical Chemistry, vol. 27, no. 11, pp. 1954-1954, 1981. 
[40] N. Wei, N. Pavlidis, G. Tsokos, R. J. Elin, and P. H. Plotz, "Clinical significance of low creatine phosphokinase values in patients with connective tissue diseases," JAMA, vol. 246, no. 17, pp. 1921-1923, 1981.

[41] J. C. O'connor, S. R. Frame, and G. S. Ladics, "Evaluation of a 15-day screening assay using intact male rats for identifying antiandrogens," Toxicological Sciences, vol. 69, no. 1, pp. 92108, 2002.

[42] M. Boas, H. Frederiksen, U. Feldt-Rasmussen et al., "Childhood exposure to phthalates: associations with thyroid function, insulin-like growth factor I, and growth," Environmental Health Perspectives, vol. 118, no. 10, pp. 1458-1464, 2010.

[43] P.-C. Huang, P.-L. Kuo, Y.-L. Guo, P.-C. Liao, and C.-C. Lee, "Associations between urinary phthalate monoesters and thyroid hormones in pregnant women," Human Reproduction, vol. 22, no. 10, pp. 2715-2722, 2007.

[44] O. Shen, W. Wu, G. Du et al., "Thyroid disruption by Di-nbutyl phthalate (DBP) and mono-n-butyl phthalate (MBP) in Xenopus laevis," PLoS One, vol. 6, no. 4, p. e19159, 2011.

[45] Y. Wu, J. Li, B. Yan et al., "Oral exposure to dibutyl phthalate exacerbates chronic lymphocytic thyroiditis through oxidative stress in female Wistar rats," Scientific Reports, vol. 7, no. 1, 2017.

[46] H. A. Aly, M. H. Hassan, H. A. El-Beshbishy, A. M. Alahdal, and A.-M. M. Osman, "Dibutyl phthalate induces oxidative stress and impairs spermatogenesis in adult rats," Toxicology and Industrial Health, vol. 32, no. 8, pp. 1467-1477, 2016.

[47] N. Nair, "Dose-dependent short-term study of di-n-butyl phthalate on the testicular antioxidant system of Wistar rats," Environmental Science and Pollution Research, vol. 22, no. 3, pp. 2196-2204, 2015.

[48] F.-M. Li, M. Wu, Y. Yao et al., "Inhibitory effects and oxidative target site of dibutyl phthalate on _Karenia brevis_," Chemosphere, vol. 132, pp. 32-39, 2015.

[49] K. Baralić, K. Živančević, D. Jorgovanović et al., "Probiotic reduced the impact of phthalates and bisphenol A mixture on type 2 diabetes mellitus development: Merging bioinformatics with _in vivo_analysis," food and chemical toxicology, vol. 154, p. 112325, 2021.

[50] K. Baralić, D. Jorgovanović, K. Živančević et al., "Combining _in vivo_ pathohistological and redox status analysis with _in silico_toxicogenomic study to explore the phthalates and bisphenol A mixture- induced testicular toxicity," Chemosphere, vol. 267, p. 129296, 2021.

[51] E. Phielix, T. Jelenik, P. Nowotny, J. Szendroedi, and M. Roden, "Reduction of non-esterified fatty acids improves insulin sensitivity and lowers oxidative stress, but fails to restore oxidative capacity in type 2 diabetes: a randomised clinical trial," Diabetologia, vol. 57, no. 3, pp. 572-581, 2014.

[52] L. Laffel, "Ketone bodies: a review of physiology, pathophysiology and application of monitoring to diabetes," Diabetes/Metabolism Research and Reviews, vol. 15, no. 6, pp. 412-426, 1999.

[53] S. K. Jain, K. Kannan, and G. Lim, "Ketosis (acetoacetate) can generate oxygen radicals and cause increased lipid peroxidation and growth inhibition in human endothelial cells," Free Radical Biology and Medicine, vol. 25, no. 9, pp. 1083-1088, 1998. 